\title{
A case report on treatment of class II jaw discrepancy with dental crowding with powerscope appliance
}

\author{
Poonam Majumder $^{1 *}$, Abhishek Singh ${ }^{2}$ \\ ${ }^{1}$ Consultant, ${ }^{1}$ Dept. of Orthodontics, ${ }^{2}$ Dept. of Dental Surgeon, ${ }^{1}$ Private practitioner, Agra, ${ }^{2}$ S.N.M. District hospital, Firozabad, Uttar \\ Pradesh, India
}

\begin{abstract}
Class II skeletal relation present with mandibular retrusion as a common etiological problem. Myofunctional appliances remain the main treatment methodology for growing patients with such problems. But when the patient reports at the penultimate end of growth curve or is non compliant, fixed functional appliances for mandibular advancement become the treatment method of choice. The present case is of a 14 year male with the chief compliant of irregular and forwardly placed teeth. On examination a skeletal and dental Class II relation with crowded anteriors was observed. Extraction of all $1^{\text {st }}$ premolars to relieve crowding along with 0.022 MBT prescription was used initially, followed by application of Powerscope Appliance for mandibular advancement. Significant improvemrnt of facial profile was seen due to forward displacement of mandible with the Powerscope Appliance. Thus it can be concluded that Powerscope Appliance is a useful novel innovation in the field of fixed functional appliances which can be successfully used to treat Class II patients.
\end{abstract}

Keywords: Class II malocclusion, Fixed functional appliance, Powerscope.

\section{Introduction}

Class II maxillomandibular relation can be attributed to various causes relating to the relative position of the maxilla, the mandible in relation to each other and the cranial base. According to McNamara, the presentation of mandibular retrognathism is a more common etiological factor for Class II patients, as compared to other factors like maxillary prognathism or combination of maxillary prognathism with mandibular retrognathism ${ }^{1}$. Skeletal deformity of any such combination warrants the need for functional appliance therapy along with contemporary orthodontic treatment. $^{2,3,4}$ The evolution of function appliance therapy has witnessed the emergence of various significant removable functional appliances such as the Activator, Bionator, Frankel function regulator, Twin Block etc and fixed functional appliance like Herbst, Jasper Jumper, Churro Jumper, Ritto appliance, Forsus fatigue resistant device, Powerscope etc. ${ }^{5,6,7,8,9,10}$

PowerScope is one of the latest innovation in Class II correction which is a direct derivative of the Herbst Type II appliance. Dr. Andy Hayes worked in conjunction with American Orthodontics to develop PowerScope. ${ }^{11}$

\section{Design and working of Powerscope}

PowerScope delivers Class II correction with a combination of patient comfort and ease of use that is unmatched among other appliances. This ready-to-use chairside solution requires no lab setup, making for a quicker and easier installation process and appointment. As described by American Orthodontics it has the following features. ${ }^{11}$
1. Ball And Socket Joint which maximizes lateral movement for improved patient comfort and acceptance,

2. Wire Attachment Nuts which ensures simple wire-towire installation reduces the need for special band attachments or headgear tubes.

3. $18 \mathrm{~mm}$ Telescoping Mechanism which is durable and will not disengage during treatment, helping avoid unnecessary emergency visits.

4. Nickel Titanium Internal Spring Mechanism 260 gm which provides spring-activated mechanism, meaning reduced treatment time compared to traditional Class II Herbst appliances.

5. Hex Head Reverse Screw thread assembly which minimizes screw loosening during treatment, while hex head design allows safe and easy appliance delivery.

This paper presents a case of a patient of Class II malocclusion with dental crowding which was treated using Powerscope in conjunction with fixed orthodontic treatment.

\section{Case Report}

A 14 year male presented with the chief compliant of forwardly placed and irregular teeth. Clinical inspection and examination revealed a convex profile with posterior divergence. Intraoral examination showed normal gingival colour and texture, adequate attached gingiva, no periodontal lesion. Class II molar and canine relation with anterior crowding was also found.

\footnotetext{
*Corresponding Author: Poonam Majumder, Dept. of Orthodontics, Private practitioner, Agra, Uttar Pradesh, India

Email address: majumderpoonam87@ gmail.com

http://doi.org/10.18231/j.idjsr.2019.019
} 


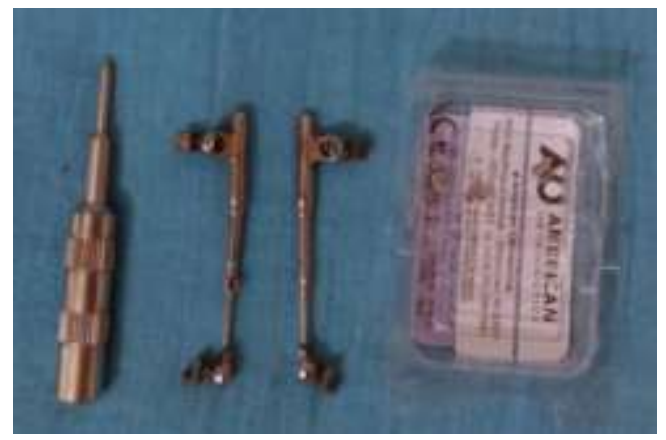

Fig. 1: Powerscope appliance

Cephalometric parameters indicate a Class II skeletal base with average growth pattern. Dental parameters showed arch length and tooth material space discrepancy, needing extraction of $14,24,34,44$. The status of growth is confirmed from hand wrist radiograph and lateral cephalogram, which shows growth is remaining.
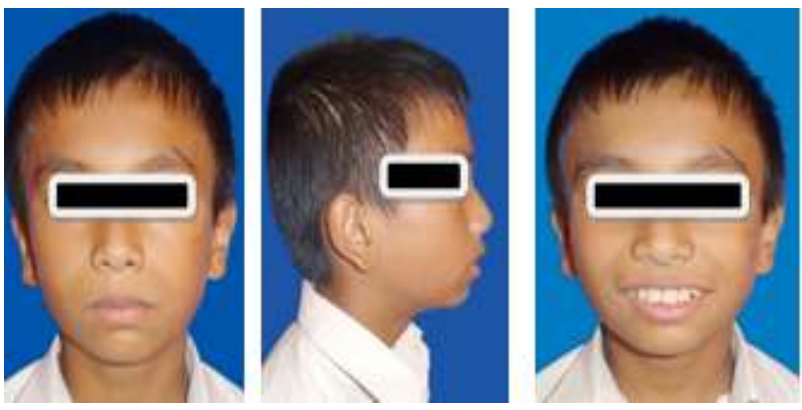

Fig. 2: Pretreatment extra oral photos
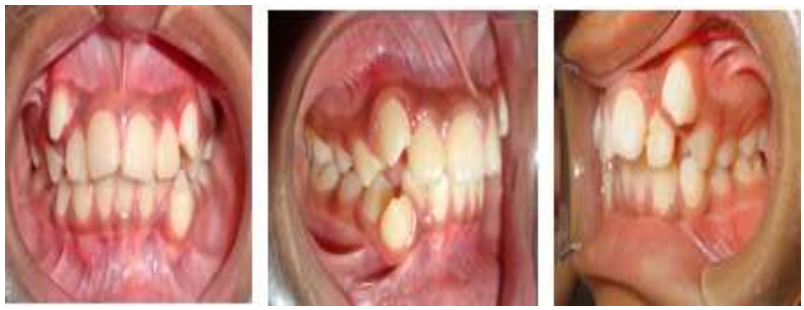

Fig. 3: Intraoral pretreatment photos

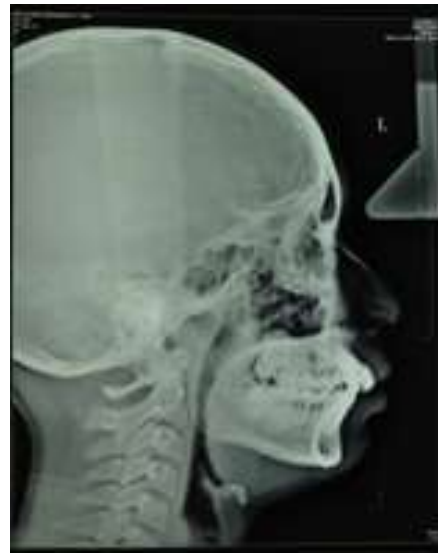

Fig. 4: Pretreatment lateral cephalogram
Table 1: Shows the pretreatment composite cephalometric analysis

\begin{tabular}{|c|c|}
\hline Sagittal skeletal parameter & Pre treatment value \\
\hline SNA & $84^{\circ}$ \\
\hline SNB & $78^{\circ}$ \\
\hline ANB & $6^{\circ}$ \\
\hline WIT'S APPRAISAL & $5 \mathrm{~mm}$ \\
\hline A-B PLANE & $-8^{\circ}$ \\
\hline ANGLE OF CONVEXITY & $10^{\circ}$ \\
\hline Vertical Skeletal Parameter & \\
\hline SN-Mand plane & $26^{\circ}$ \\
\hline FH-Mand plane(DOWNS) & $25^{\circ}$ \\
\hline FMPA(TWEEDS) & $26^{\circ}$ \\
\hline FACIAL AXIS & $3^{\circ}$ \\
\hline Y AXIS & $65^{\circ}$ \\
\hline JARABACK RATIO & $71 \%$ \\
\hline SN-OCC plane(STEINERS) & $10^{\circ}$ \\
\hline
\end{tabular}

\section{Treatment objectives}

1. Reduce lip protrusion and profile convexity

2. To improve soft tissue esthetics

3. To achieve Class I molar relationship,

4. To achieve class I canine relationship bilaterally.

5. To achieve ideal overjet and overbite.

6. To maintain co-incident dental and facial midlines

7. To achieve long term stability

\section{Treatment Plan}

1. Fixed Mechanotherapy $\{0.022 \times 0.028$ inch MBT Slot $\}$ followed by Fixed functional appliance i.e. Powerscope.

2. Extraction of 14, 24, 34,44.

3. Alignment and levelling of both the arches.

4. Enmasse retraction in both arches.

5. Fixed functional appliance Powerscope for mandibular skeletal correction

6. Finishing and detailing of occlusion.

\section{Treatment Progress}

Levelling and alignment was started using 0.014 Niti archwire in upper and lower arch. Extraction space was mainly used for alignment of the crowded anteriors. This was followed by placement of $0.019 * 0.025$ Stainless steel archwire in upper and lower arches. A $5^{\circ}$ torque was place in the anterior mandibular archwire to prevent flaring. Powerscope was then used for mandibular advancement as shown in Fig. 5.

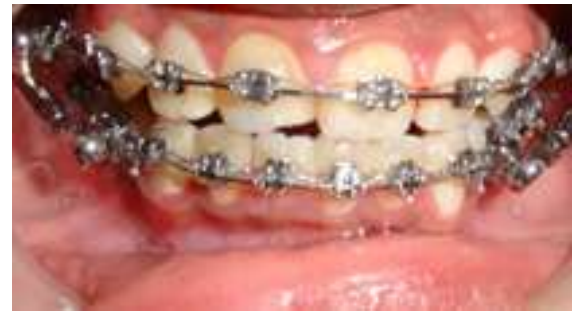

Fig. 5: Powerscope used for mandibular advancement 
Table 2: Changes in cephalometric parameters after treatment

\begin{tabular}{|c|c|c|}
\hline Sagittal skeletal parameter & Pre treatment value & Post treatment value \\
\hline SNA & $84^{\circ}$ & $82^{\circ}$ \\
\hline SNB & $78^{\circ}$ & $80^{\circ}$ \\
\hline ANB & $6^{\circ}$ & $2^{\circ}$ \\
\hline WIT'S APPRAISAL & $5 \mathrm{~mm}$ & $-6^{\circ}$ \\
\hline A-B PLANE & $-8^{\circ}$ & $9^{\circ}$ \\
\hline ANGLE OF CONVEXITY & $10^{\circ}$ & $29^{\circ}$ \\
\hline Vertical Skeletal Parameter & & $23^{\circ}$ \\
\hline SN-Mand plane & $26^{\circ}$ & $27^{\circ}$ \\
\hline FH-Mand plane(DOWNS) & $25^{\circ}$ & $2^{\circ}$ \\
\hline FMPA(TWEEDS) & $26^{\circ}$ & $61^{\circ}$ \\
\hline FACIAL AXIS & $3^{\circ}$ & 67.5 \\
\hline Y AXIS & $65^{\circ}$ & $11^{\circ}$ \\
\hline JARABACK RATIO & $71 \%$ & \\
\hline SN-OCC plane(STEINERS) & $10^{\circ}$ & \\
\hline
\end{tabular}
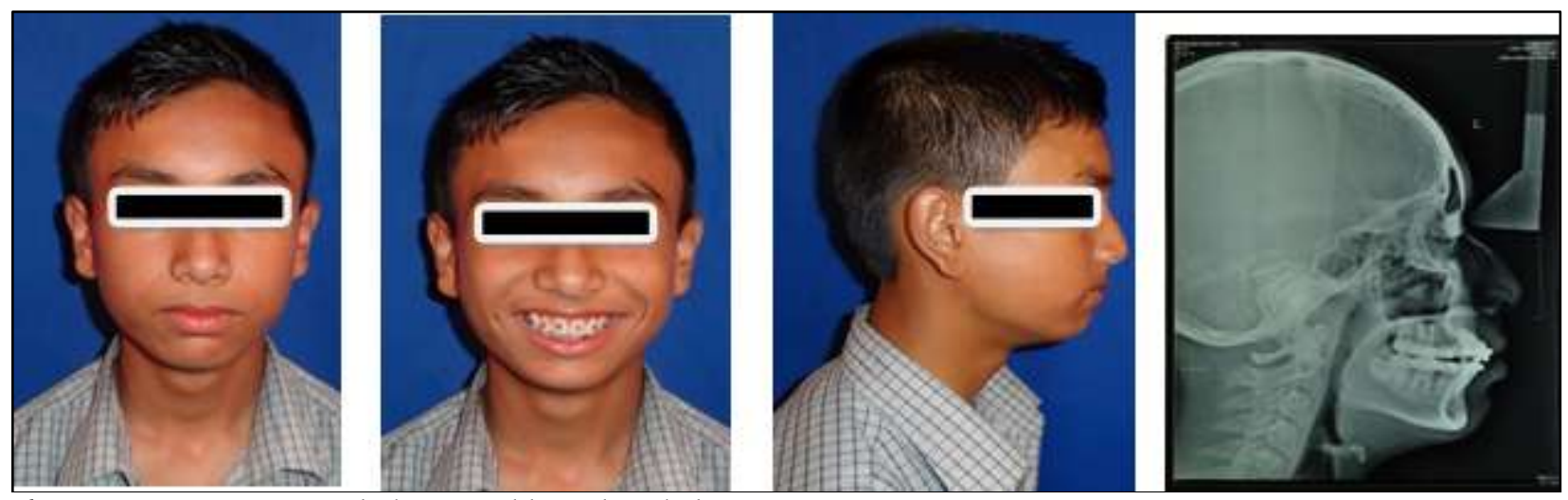

Fig. 6: Post treatment extraoral photos and lateral cephalogram.
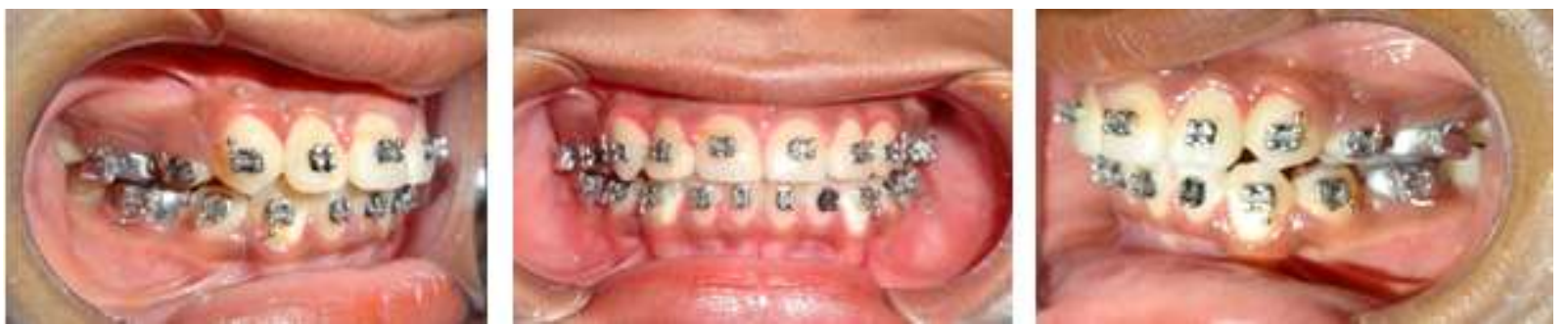

Fig. 7: Post treatment intra oral photos

A significant improvement could be noted in the facial profile after the advancement of mandible. The appliance was comfortable to the patient and also did not cause any incidence of debonding of lower canine bracket or dislodgement of the assembly of the appliance.

\section{Discussion}

Fixed functional appliances have several advantages which has encouraged the repeated need for evolution and innovation in their design time and again ${ }^{12}$. They are free of patient compliance, ensure 24 hours wear which provides with continuous force delivery for effective functioning and hence more useful in the cases where limited percentage of growth is remaining. ${ }^{12,13,14}$ These advantages have therefore lead to the continued research and evolution in this field.

Powerscope appliance ${ }^{11}$ has features which combine the advantages of both rigid fixed functional appliance and flexible fixed functional appliance. In the present case Powerscope appliance proved to be a useful instrument in advancing the mandible. The ball and socket design provided patient comfort, at the same time the $18 \mathrm{~mm}$ telescopic mechanism ensured no episodes of disengagement from the wire assembly. Wire attachment nuts and hex head screws ensured easy chairside delivery and removal of the appliance. 


\section{Conclusion}

Class II cases with other combination of problems like crowding, as in the present case, sometimes warrants the necessity for extraction, followed by mandibular advancing. ${ }^{13}$ However the first treatment objective should always be correction of the underlying skeletal problem with functional appliance when within the growth period. ${ }^{14,15}$ The technological advances, in the design mechanism of various appliances, should be taken to provide maximum benefit to the patient in terms of comfort and also treatment result. Powerscope being one such new appliance can be used by orthodontists, for mandibular advancement in treating, Class II skeletal discrepancies. More studies should be done on this appliance to further supplement more knowledge about the usefulness of the same and also define the drawbacks which will help in further innovations.

\section{Declaration of patient consent}

The authors certify that they have obtained all appropriate patient consent.In the consent form the patient(s) has/have given his/her/their images and other clinical information to be reported in the journal.The patients understand that their names and initials will not be published and due efforts will be made to conceal their identity, but anonymity cannot be guaranteed.

\section{Source of Funding}

None.

\section{Conflict of interest}

None.

\section{Reference}

1. McNamara JA Jr. Components of class II malocclusion in children 8-10 years of age. Angle Orthod 1981;51:177-202.

2. Proffit WR. Malocclusion and dentofacial deformity in contemporary society. Contemporary Orthodontics. 4 th ed. St. Louis: Mosby Elsevier; 2007;3-23.
3. Graber TM, Rakosi T, Petrovic A. Dentofacial Orthopedics with Functional Appliances. St. Louis: C. V. Mosby Co.; 1997;346-52.

4. Coelho Filho CM. Mandibular protraction appliances for class II treatment. J Clin Orthod 1995;29(5):319-36.

5. Ritto AK. The Ritto appliance-A new fixed functional device. Orthod Cyber J 1999(http://www.oc-j.com/ ritto/ritto.htm).

6. Jasper JJ. The Jasper Jumper a fixed functional appliance. Sheboygan, Wisconsin: American Orthodontics, 1987.

7. Pancherz H. Treatment of class II malocclusions by bite jumping with the Herbst appliance: a cephalometric investigation. Am J Orthod 1979;76(4):423-42.

8. Ruf S, Pancherz H. Herbst/multibracket appliance treatment of Class II division 1 malocclusions in early and late adulthood. A prospective cephalometric study of consecutively treated subjects. Eur J Orthod 2006;28(4):352-60.

9. Heinig N, Göz G. Clinical application and effects of the Forsus spring. A study of a new Herbst hybrid. J Orofac Orthop 2001;62:436-50.

10. Vogt W. The Forsus fatigue resistant device. J Clin Orthod 2006;40:368-77.

11. Available from: http://www.americanortho.com/powerscope.html.[Last accessed on 2016 may 07].

12. Nelson B, Hansen K, Hägg U. Class II correction in patients treated with class II elastics and with fixed functional appliances: A comparative study. Am J Orthod Dentofacial Orthop 2000;118:142-9.

13. Moyers RE, Riolo ML, Guirek KE, Wainright RL, Bookstein FL. Differential diagnosis of class II malocclusions. Am J Orthod 1980;78(5):477-94.

14. Bishara SE, Ziaja RR. Functional appliances: a review. Am J Orthod Dentofacial Orthop 1989;95:250-8.

15. Wahl N. Orthodontics in 3 millennia. Chapter 9: Functional appliances to midcentury. Am J Orthod Dentofacial Orthop 2006;129:829-33.

How to cite this article: Majumder $\mathrm{P}$, Singh A, A case report on treatment of class ii jaw discrepancy with dental crowding with powerscope appliance, Int Dent $J$ Student Res 2019;7(3):75-8. 